Article

\title{
Ecophilosophical Principles for an Ecocentric Environmental Education
}

\author{
David Molina-Motos
}

Escuela Internacional de Doctorado, Universidad Nacional de Educación a Distancia (UNED), 28015 Madrid, Spain; dmolina5@alumno.uned.es

Received: 29 December 2018; Accepted: 11 February 2019; Published: 13 February 2019

\begin{abstract}
As environmental slogans have been permeating the social imaginary and permeating the conceptual and axiological dimensions of the different educational currents, Environmental Education has been prompted to define its own specific nature in contrast to the supposedly more integrative educational movements. In contrast to the historical or meta-theoretical strategies of specification and foundation of environmental education, we propose the establishment of some principles derived from genuinely ecological and ecocentric environmental philosophies; the ecophilosophies. This work reviews - in a conciliatory framework and with a pedagogical interest in mind-the most significant contributions of land ethics, deep ecology, social ecology, ecofeminism and the change of paradigm ecologies. The result is a set of facets, key categories and features that offer an integrated and synoptic view of how Ecocentric Environmental Education (EEE) could be based on ecophilosophical principles. In addition, the contrasting features that define those non-ecocentric perspectives of Environmental Education are proposed, and a deconstructive transition of these in alliance with another reconstructive ecophilosophical feature is suggested as the central intention of the Environmental Education methodology. Finally, the value of the theoretical proposal is defended as a foundation and framework for future pedagogical specifications and methodological developments.
\end{abstract}

Keywords: environmental education; ecophilosophy; environmental ethics; deep ecology; social ecology; ecofeminism; ecocentrism

\section{Introduction}

The debates in the field of Environmental Education (EE) that arose a couple of decades ago around Education for Sustainable Development (ESD) [1] have been revitalized by the proposals of the Global Citizenship Education (GCE) [2]. The fact that similar arguments are repeated by advocates of the possibility of integrating EE into a larger educational movement manifests the idea of a partial and superficial understanding of EE. We do not believe that it is possible to successfully integrate EE into any educational movement that does not also assume the radicality of the principles that underlie EE, differentiate it, and propose it as a whole ecological pedagogy in itself.

This paper tries to describe the genuineness of EE through a synthetic proposal of principles culled from those environmental philosophies committed to an ecological vision (ecophilosophy). We believe that "econcentrism" is the differentiating feature of EE, from which a complete world-view is developed that is incompatible with a superficial conception of environmental problems. Environmental educators tend to be eager for curricular and methodological guidelines that facilitate the design and effective development of their practical work. However, can we ensure that these educators operate critically and reflexively from the assumptions of this genuine EE? For our part, we assume the perspective of critical pedagogy [3-5], considering that teachers should be given an opportunity to build their own "epistemology" or world-view reflectively and autonomously, because then their practices and methodological choices will take on real meaning. 
This article is part of a research project that seeks to explain and develop the connection of EE with an "integral" perspective of ecological thinking [6-9] within the framework of a post-formal conception of education $[10,11]$ that allows to define a transformative learning model $[12-15]$ for the training of these environmental educators. Within this sequence this paper is therefore focused on epistemologically framing EE in this world-view and not so much in proposing ways of implementation or methodological guidelines, which, although they are essential, are out of the scope of this work.

A strategy for the foundation of Environmental Education (EE) is to describe its characteristics using its own process of historical gestation. This process is mainly driven by adaptations to the environmental challenges, the public policies of the international institutions, the changes in the social imaginary regarding the "ecological problems", and finally by the critical debates that all of this has provoked among the different actors of the EE (academics, educators, activists, and so on). We can call this constitutive process the "EE tradition"; and consequently, one way to establish the features of a specific current of EE is through an interpretative and/or critical exposition of that tradition. Likewise, some meta-theoretical efforts [16] can be used to establish frameworks that facilitate a more solid foundation for EE, considering the different currents, orientations and practices.

Our proposal of theoretical foundation explores a complementary strategy and tries to strengthen a conception of EE that situates it in the field of "ecological thinking" as a genuine world-view that arose in the seventies and was developed from diverse ecophilosophies. In short, this work inquires, from the aims of a pedagogy with a genuinely socio-ecological vocation, into what is reconcilable and complementary amidst the diversity of proposals of ecological and philosophical thought and how this set or system of principles could complete a vision of an EE that is capable of critically and creatively integrating the historical currents of this educational movement.

It is necessary to clarify that, after more than four decades of philosophical thinking around "environmental issues", the panorama of the different currents and trends is profoundly diverse and overwhelmingly large. However, not all of this production has a fundamental inspiration and basis in genuinely ecological thinking, usually it supposes an approach to environmental issues from theoretical positions not necessarily close to philosophical environmentalism. Thus, Sauvé and Villemagne [17] have explored from a pedagogical view eleven eco-ethical trends, not limited exclusively to ecocentric ones, with the aim of showing the variety of attitudes and values available in a pluralistic formulation of EE. In contrast, our work, which precisely aims to provide a foundation of EE from the genuine philosophical environmentalism, will focus only on those currents that can be properly called "ecophilosophies" and will try to offer a coherent set of facets, categories and theoretical traits constitutive of an ecocentric EE.

\section{An "Ecology" of Environmental Philosophies}

In the early eighties John Rodman [18] proposed a typology of environmental thought currents that roughly corresponded to its historical evolution. The first three typologies or stages referred to the "conservation of resources" (prudential stage), the "protection of natural spaces" (reverential stage) and "moral extensionism" (respectful stage). In short, these typologies include those views that can be graduated between a new instrumental interest in nature and the affirmation that non-human beings have rights (and therefore that human beings have obligations towards them). This last position, which tries to extend our conventional morality (and its philosophical foundations) especially towards sentient beings, being more daring, does not become fully "ecological" for most ecophilosophers because it is not yet untangled-despite its non-anthropocentric scope-of an anthropomorphic and self-referential approach.

Rodman's fourth type is "ecological sensitivity" and represents an inclusive stage of development that points to a conglomerate of new "perceptions, attitudes and judgments" that rest on a renewed proposal of metaphysics, theory of value and ethics. What the ecophilosophical tradition has tried to do since the mid-1970s is to value the viability of this project and make substantive proposals. The result is far from being a homogeneous and consensual theoretical corpus. However, it is common to the literature of ecophilosophy to make a distinction between two philosophical approaches that 
represent, on the one hand, the three first types of Rodman, and the fourth on the other. Adjectives that are often used in opposition to refer to these two strands are "environmental/ecological" $[19,20]$ or "light green/dark green" [21]. This differentiation is directly linked to the concepts of "shallow or deep" ecology of Arne Naess [22]. Indeed, Naess was proposing to transcend the conventional ethical consideration-however extensive that it may be proposed-towards an ecologically inspired philosophical concept (deep and dark green). It is within this current where we believe that EE should enrich its principles if it is to be a genuinely ecological field of knowledge and action. For this purpose, a synthesis of ecophilosophical principles is required. Bearing in mind an intention of pedagogical construction, these principles are not to be blocked by the critical discussions about the subtle (although pertinent) theoretical incompatibilities, but they are to facilitate complementary points of views.

\subsection{Ecoethics: the Land Ethic}

The decade of the seventies represented the beginning of environmental ethics as a formal field of reflection within academic philosophy. Its development has followed multiple paths according to the emphasis on its fundamental or applied character, its ecocentric or anthropocentric basis, its individualistic or holistic emphasis. In view of Rodman's classification and motivated by an ecological sensitivity, we will focus on an early ecocentric and holistic approach: "the land ethic" that was proposed by Aldo Leopold [23] and published posthumously in 1949, two decades before the formal start of environmental philosophy. Later, J. Baird Callicott $[24,25]$ has continued in the academic field the work of Leopold, basing and extending his theses. For Leopold [26] (p. 96):

All ethics so far evolved rest upon a single premise: that the individual is a member of a community of interdependent parts. [ ... ] The land ethic simply enlarges the boundaries of the community to include soils, waters, plants, and animals, or collectively: the land.

Ultimately, for Leopold, the ecological community is "a community of interests" in the sense of being globally a symbiotic community; that is, a community in which, despite having competitive local strategies, a global evolutionary tendency is shown to increasingly cooperation modes of coexistence. The evolutionary moment at which our human society has arrived already implies an ethical conscience that understands that the role of the human species is to be a "plain member and citizen" [26] (p. 97) within the community of the earth. This understanding is not merely utilitarian with respect to the incipient certainty that our survival depends on it; nor it is an awareness based on respect for those beings capable of developing "utilities" or interests (as some movements for animal liberation states). The ecological conscience of Leopold is holistic (and not merely "extensionist" in the sense that we have commented), since it redefines the human being as a symbiotic being. We could say that this ecological citizenship does not mean merely living, but "inter-living". Therefore, the sense of obligation for humans that arises from this moral approach does not occur by an awareness of moral and legal rights, but by an intellectual, emotional and aesthetic perception of value (of the inherent value of life and its environment). Respect for this value and its preservation is therefore the basic moral criterion of right and wrong, of good and bad: "A thing is right when it tends to preserve the integrity, stability and beauty of the biotic community. It is wrong when it tends otherwise" [26] (p. 108). This statement has been interpreted in different ways, but fundamentally serves to recognize the value of both individuals and ecosystems. It also reminds us of the union between ecosystems and culture. Nevertheless, we have to bear in mind the naturalistic tendency to extract too many moral and normative conclusions from the behavior of nature.

\subsection{Deep Ecology}

The land ethic advanced an ecocentric ethic but presupposed an ontology that was still to be developed. Deep ecology framed that task in an absolutely relational ontology that affirms the radical interdependence of all beings. Its beginnings are thanks to the Norwegian philosopher Arne Naess in the seventies, and since then deep ecology has been the main reference in the field of ecophilosophy; 
so the rest of the proposals have needed to engage in dialogue or contest with it to defend their theoretical proposals.

For Naess, it is superficial to look for the causes and remedies of environmental destruction in policies and concrete decisions, because these are only the manifestation of something deeper: a false ecological conscience. This false conscience is based on the idea that what is not human has no value in itself, but that it has value to the extent that it is valuable to human beings. Therefore, human beings have the right (or even obligation) to do with the non-human what he wants or other human beings allow them [27] (p. 229). These are precisely the arguments that define anthropocentrism.

Every anthropocentric vision develops in two ways, consciously or unconsciously. On the one hand it is shown in the passive and impoverishing attitude of human chauvinism; but on the other, still more destructive, it adopts an active form of imperialism and its oppressive effect on natural beings [28] (p. 21). Therefore, the liberating task of deep ecology is to eliminate the anthropocentric domination of nature by developing a genuinely ecological (ecocentric) consciousness. But this does not happen by a deontological imperative, nor by a prudential calculation, but rather by an ecological intuition of longing (not necessarily intellectual) for authentic interrelation. Nature, if it is a source of value, is the house (oikos) where we can find our center. However, a radically relational principle can only lead to blurring the identity boundaries of beings; so the starting point-especially for an Arne Naess deeply influenced by Buddhism-is to find in the ego the root of all illusory separation with nature. That is why the central precepts of Naess's view [29] (pp. 80-81) are: "maximize self-realization (universal and non-egoistic)", "maximize symbiosis" and "maximize diversity"; which are analogous expressions with a complementary explanatory capacity. To understand them, it is necessary to notice the distinction between the "Self" (with capital letters) and the individual "self" (with small letters) narrow and generally egocentric. In short, the mission of deep ecology is to offer the resources for the self to understand the absolutely relational essence of the world and life as a systemic and complex whole; in other words, deeply ecological. When all this happens [30] (pp. 163 et seq.), the ecological self is discovered fluidly and naturally inhabiting the Self and thereby enabling both its fulfillment and the fulfillment of the rest of life interconnected with it.

Conversely, unblocking the development of the complex diversity of beings allows the flowering of the "Self" in which the "self" participates. The natural and fluid form of participation is the symbiosis, which Naess interprets from Gandhi's philosophy of nonviolence. The development of this ecological or expanded self is a process of "identification" in communion with other beings [31], which implies an ethical conception of egalitarianism or "biospheric democracy" [32] (p. 67 et seq.). This process of identification is not merely an undifferentiated dissolution or fusion, but it is genuinely ecological and complex in the sense of occurring promoting a greater diversity, uniqueness and specificity, and therefore a greater self-determination and freedom. At least in their intentions, deep ecology does not enact a "triumphant holism" in which individuals submit to the totality. On the contrary, what is at issue is to "liberate" the potential of the beings hindered by the relations of subjection and exploitation that are expressed in the anthropocentric world-view. In short, anthropocentrism itself is an enemy of the human spirit since it misinterprets the desire for self-realization in an exclusionary and egotistical way (as a human species and as individuals), and therefore it supposes also the denial of such possibility to the rest of life on the planet. Self-realization is thus equivalent to the aspiration of realization of all beings.

According to the deep ecology, these ecological principles allow us to reformulate our philosophical and spiritual roots (Christian, Buddhist, secular ... ) in ecosophical terms. This "ecosophy" is the knowledge of our terrestrial existential ground. Deep ecologists consider that this view of the world, needing to be compatible with the scientific world-view, cannot be limited to it. A change of emphasis from science to wisdom is necessary [32] (p. 74). However, deep ecology does not want to be a prudish or unarmed philosophy. It is a platform, a base of truth to embrace in order to resist and advance social transformation. Its ultimate goal is to work for society to harmonize with nature and for ethics and politics to be merged in the need for a life-affirming activism. 
Finally, it seems to us that, with more or less originality, and with the preventions about restraining abstraction and mysticism, deep ecology entails a valuable pedagogical dimension by bringing the responsibility of ecological change to the field of the conscience of the person.

\subsection{Philosophies of Planetariness and the Paradigm Shift}

Some critics of deep ecology believe that the necessary ecological transformation is more complicated than merely intensifying a self, since this is in a complex relationship with the cultural whole that surrounds us. In short, it is not primarily a new kind of person what we are looking for, but a new vision of the world (world view) or paradigm. According to the followers of paradigm shift, a foundation of the relational principle is sought in the philosophies and scientific theories related to this concept. For these authors (e.g., Capra [33]) the inheriting paradigm of modernity involves merely retouching of the rationalist and Newtonian perspective, which involves a mechanistic, atomistic, reductionist and deterministic ontology and adopts a positivist, rationalist, analytical, formalistic and disciplinary epistemology. It represents a naive arrogance, because it contemplates the complexity of the world in a reductionist way, and is motivated by the ambition of control of modern man, especially by the economic interest of the techno-industrial powers. The contemporary socio-ecological crisis is the consequence of such arrogance.

The role of the ecophilosophers of the paradigm shift is to dismantle this world-view and find the support to strengthen a new paradigm that arises from a multitude of fronts where the modernist paradigm has clashed with its own limits: quantum physics, thermodynamics of irreversible processes, chaos theory, fractal mathematics, artificial life, complexity sciences, and so on. This paradigm interprets the relational principle within the framework of philosophy derived from systems theory and second-order cybernetics, which reintroduces to the observer himself (subject) as a systemic element of the world. These inspire a meta-theory that attempts to articulate all areas of life (mind and society included) in an interdependent and systemic whole. Ecological thinking is now genuinely ecological not because it accounts for the biological or economic interrelations in an ecosystem, but because it understands the term "ecological" as the indissoluble systemic union of these with the social, cultural and mental. In short, the foundation of the real ceases to be simplicity and becomes complexity [34]; whose epistemological consequences draw a substantially new world-view. A vision capable, among other things, of articulating an explanation of life and evolution as a web [33], a self-organized process that balances an indetermination and inherent creativity with the invitation to endless knowledge. A global apprehension of the reality within the framework of this paradigm cannot occur from the mere disciplinary sum of fragmentary knowledge, but it integrates and organizes it from a transdisciplinary conception of knowledge.

This paradigmatic vision needs to be applied to the actual world, where the "web of life" binds the macroscopic and the microscopic world. Regarding the macroscopic approach, it finds in the "Gaia theory" by James E. Lovelock [35] a powerful support, as well as in the contributions of Lyn Margulis [36] for the microscopic approach. The idea defended by both states that "the living matter of the Earth and its air, oceans and surface form a complex system that can be considered as an individual organism capable of maintaining the conditions that make life possible on our planet" [35] (p. 8). Therefore, the systemic view finds in the Earth as a system both an irrefutable limit and the clearest criterion for the demarcation of systemic identity: planetariness as a "community of destiny" [37]. From this moment, the environmental vision will gravitate around two recurring themes: the first is to establish the dire economic and demographic consequences of an ideology of unlimited growth in a material and spatially finite planet [38]; and the second is to try to clarify and communicate that the homeostasis of the terrestrial system is threatened by the human being. It should be noted that a catastrophic approach to environmentalism has motivated ethical, philosophical and authoritarian (eco-fascist) political proposals based on the fact that survival is more important than the fundamental rights of people (especially people of the countries of the Global South). The existence of this current demonstrates that the different approaches to environmentalism are not ideologically and politically equivalent and that an essential 
self-critical ingredient is necessary in the form of a system of theoretical guarantees that prevents any authoritarian drift in our EE proposal.

\subsection{Ecofeminism and Ecophenomenology}

The ecological self sustains embodied by a productive and reproductive corporeality and animality. Nevertheless, this basic condition can be denied for the sake of a higher unitary consciousness, or-within an ecocentric framework - it can be affirmed as the authentic link with the earth community. A direct use of this affirmative intuition is given by the eco-phenomenological approach in the traditions that emerged from Merleau Ponty, Martin Heidegger or the recent ecohermeneutics. All these areas of work "return" to the vivid experience of our worldliness and try to understand this experience in an ecological sense and to untangle it from its inherent mediations. In short, they warn us about the naivety of an objective representation of nature with which to commune (externally or internally).

Another proposal that arises from corporeality-considered from a gender perspective-is ecofeminism. Ecofeminism is not proposed as an intersection or application of feminism and environmentalism, but rather a reformist movement of both. The ecophilosophy cannot ignore the principles of a patriarchal and androcentric worldview and its effects of oppression on women and nature. Ecofeminism conceives patriarchal power structures not only as institutional, but also as some kind of mentality [39] (p. 84) that defines "nature" and impregnates the position, function and subordinate value of the feminine (and the social role of women). Ecofeminism criticizes the role of "invisibility" that the patriarchal society has given equally to women and nature, mainly considering their contribution to the production and reproduction of life as "unproductive" in economic terms [40].

As we can check, ecofeminism is not an application of feminist theory, but a foundational revision based on the assumption that the nature/culture fracture is the basis of the exploitation of women. Amending this fracture can only happen after (or at the same time, but not before) freeing the human species from the obstruction of patriarchy. It cannot be "before" -as deep ecology suggests- since it is impossible to tackle anthropocentrism without this critical reflection: that the internal operating mechanism of anthropocentrism is androcentrism and a patriarchal mentality that contaminates axiologically and epistemologically every transformative enterprise. The activation of change can only be operated from this mechanism and (for some ecofeminists) led by the oppressed historical subject: women.

The work of ecofeminism would consist in subverting the dualistic value structure that permeates Western culture as a whole and that opposes nature (inferior) to human, culture, reason, mind, spirit (superior); at the same time traces the contrast pairs (superior/inferior): male/female, mind/body, owner/slave, reason/matter, rationality/animality, reason/emotion, freedom/need, universal/particular, civilized/primitive, production/reproduction, subject/object, I/other [41] (pp. 41 et seq.). It would not be a question of reversing the value of the pairs, but of transcending them in inclusive categories; in short, "feminizing" society and culture.

Ecofeminism does not abandon the environmental radicalism of a relational vision of the world; on the contrary, it insists on it from the faculties and attitudes granted by an overcoming conception of the oppressive dualisms. For that reason, ecofeminist thinkers criticize the androcentric bias that they find in the tendency of arrogance and abstraction of deep ecology, and they propose to add a warm approach of the ecological self to the world. It supposes therefore an approximation that balances the rational, the intuitive and the affective and that celebrates the difference of the singular as love, compassion, generosity, and friendship. In contrast to liberal ethics of rights, which reflect the atomistic and individualistic fear of the power of others over us, a relational ethic is proposed, which switch the focus on power by the idea of care and accompaniment in the flourishing of value. This perspective, which is ethical but also political, cannot forget the historical process that explains the real situation women suffer. This establishes a singular "difference", a singularity to be overcome (feminism of equality) or a singularity that empower and develop (feminism of difference). 
Ecofeminism that deals with the historical and cultural roots of the oppression of nature and women has analyzed the factors of this "difference" and how patriarchy has built upon it a set of interested distortions. For example, Caroline Merchant [42] (pp. 164 et seq.) explored how the parents of the "scientific revolution" legitimized the exploitation and conquest of nature through an imaginary with sexual resonances. On the one hand, this highlights the axiological burden and attitude of the scientific epistemology of modernity, and on the other, points out the communion of destiny of woman and nature, both made "available" for man. However, is there a natural fundament of such communion? This is an issue widely discussed within ecofeminism. On the one hand, there are those who believe that-from this communion-a "privileged point of view" of women would emerge, a special connection with nature, and with it a differentiated role of women in the feminization of the world. On the other, there are those who believe that this difference could legitimize part of the unmasked dualisms. Warren, for example, admits the special connection of women with nature, not in an essentialist way but because of the role historically and socially assigned during their upbringings. In short, having been excluded together with nature has allowed women to develop insights and empathies that are privileged but not exclusive to them. For other authors [39] (pp. 77 et seq.) this idyllic relation with nature is nothing more than a romantic vision, in analogy to the myth of "mother earth", which does not correspond to the actual industrial woman of modernity (which is precisely where ecofeminists are located as authors). This debate within ecofeminism has to do with the risk of an excessively "essentialist" burden in its commitment to the "difference" in the female relationship with nature [43] (pp. 79 et seq.).

Ultimately, ecofeminism reveals that the supposed objectivity in the deep ecologists' conception of nature and in its value, is not such. Ecofeminist analysis goes beyond gender and reminds us that the interpretation of nature cannot advance without debugging it from the same mediations or conceptual categories that have built the antagonistic human/nature relationship [42]. It is not simply a question of reversing and changing the accent in the second, hoping that this will mean a form of ecological humanism. The aim is to overcome the false dualisms, starting from a new system of more inclusive categories. A set of categories that fosters a more integral (ecological) vision of what human beings are (mental, affective, spiritual, corporal ... ) and what kind of relation with nature should be (focusing on "care").

\subsection{Social Ecology and Environmental Justice}

Social ecology inherits part of the critical and categorical apparatus of Marxism as it has generally been interpreted by anarchist libertarianism, and aims to equip ecologist thinking with a "philosophy of history" and a "social analysis" that does not conceal the conflict inherent in the human being as a collective and reflective subject. This reflexivity is precisely what explains how there is a dialectical relationship between society and nature. So, this dialectical relationship-within an evolutionary and cultural framework - explains that each one is a manifestation of the other [44] (p. 34). On the other hand, this same reflexivity confers a distinction to the human species with respect to the rest of species. Forgetting this distinction is the main error of deep ecology, as it collaborates in the "contradiction" that the capitalist system supposes in the development of a history whose authentic meaning it would be the overcoming of the alienation of the human being, which can be understood as the conciliation of the human species with itself, with other species and with the dynamics of the planet. Indeed, for this current, the capitalist system misinterprets this distinction as separation and superiority. On the one hand, it turns capital and nature into antagonist, and on the other it establishes a social and cultural logic of domination that is embodied in the hierarchical organization of the society and manifests itself in the exploitation of human beings and nature [19]. This logic of domination is also established in the deterministic and economicist vision that pervades the hegemonic social imaginary, which is constantly legitimized in narratives and loops of self-confirmation and which infuses in each person the denial of all genuine individual autonomy. 
The main objective is, especially for the eco-anarchists, to subvert these narratives and all forms of political, economic and scientific monologism that is present both in the market ecology or green capitalism, and in the ad hoc environmentalism of the social-democracies. It is therefore necessary to strengthen the active and critical role of the autonomous individual, counteracting those who propose to merge her into a contemplative vision with nature or to tie her as a mere thread in the holistic web of life. So, the key point is facilitating communities of dialogue and considering the dialogue and the autonomous and cooperative participation as that distinctive form of our species among other species, all of that within the framework of a dialectical conception of the finitude of the planet.

Ecosocialism has been especially critical of naive narratives about finitude, scarcity and conservationism. And it seems reasonable-from a dialectical representation of nature [45] and our symbiotic and symbolic relationship as humans-to recognize both the ecosystem limits and the power games manifested in the supposed consequences of these limits, especially in the establishment of supposedly objective limitations imposed on several human communities. Again, the statement of participation and collective inquiry into decision-making are proposed as a system of guarantees against any temptation of dogmatic environmentalism. In short, they work both as an alternative to technocratic monologism and as a process of citizen awareness and individual and community development.

Thus, in contrast to a shallow social revisionism of some environmental policies or the merely intuitive slogans of a counter-cultural environmentalism, social ecology proposes a critical explanation of the historical engine of the socio-ecological crisis, from whose inherent contradiction a new form of reflexivity can emerge. That promotes a socially transformative action. The role assigned to this genuinely human reflective distinction may be considered as anthropocentric [21] (p. 50), but we interpret it as a necessary step for a more complex and less naive integration than the slogans of certain "flat biospheric egalitarianisms". An egalitarianism that is insufficiently elaborated lacks both a viable ethical normativity and a socio-political analysis capable of guiding a socially transformative praxis.

Besides, social ecology can reconcile the absolutely pertinent principles of the movements for "environmental justice" [46] and the "environmentalism of the poor" [47]. The former shows how the human rights policy merges with the environmental dimension, the later-in the framework of a political environmentalism and a distributive justice-proposes an urgent reflection on discrimination in the allocation of resources and socio-environmental impacts. Ultimately, an ecocentric perspective-as an aspirational and regulatory idea-cannot be indolent with human suffering, nor subsume it, perplexed, within the immensity of the suffering of other beings. This perspective should also encourage immediate action in our actual world, a world urged to respond to the appeal of other human beings and the challenges to their political organization. It should also acknowledge the uniqueness of our human environment, built by dwelling in a singular place and an historic moment. Also, we have to guard the knowledge and the experiential richness that the unique contact of each culture with ecosystems has fixed in language, myths, art, techniques, and spirituality.

The incarnation of an ecological self is therefore also necessarily cultural; so, it must be critical of those uniform and excluding ways of "uprooting" people from their places. Without this inter-cultural perspective, one could fall into a form of environmental colonialism that denies true human diversity. Thus, in contrast to the developmental discourse of sustainability within the framework of "globalization", there is an effective practice of the singular communities that understand sustainability comprehensively, where it is pertinent to attend to the identity, meaning and sense of the individuals and communities.

\section{A synthetic Proposal of Eco-Philosophical Principles for Environmental Education}

If the ecosophies postulate that human moral misery derives from a miserable relationship with nature, social ecology turns it around and affirms that it is the conflictive relationships between humans that ultimately prevent a collectively healthy relationship with nature. From a pedagogical point of view, both perspectives are compatible and complementary. In this sense, the role of an ecological pedagogy is to think and propose educational alternatives that embrace the shared aspiration of 
all ecophilosophies to achieve the fulfillment of life on the planet, which also logically implies human life. From this point of view, we believe that EE has the capacity to look in a conciliatory way at the differences between the ecophilosophical proposals as different complementary dimensions of consideration and, above all, of strategy.

The result is a conceptual framework that suggests grouping the possible facets of an ecological pedagogy and extracting the principles of a viable deep, wide, warm, complex and supportive EE, as is reflected in Table 1. This table synthesizes the selected contributions of each current of thought that we have exposed in this work, also highlighting as key categories the most general proactive and critical attributes that would define their contribution to EE. It is important to note that the set of what we have called "traits" - really concentrating terms of sets of ideas-are not exclusive of a "facet" or a current of thought, but arise and are understood from their interdependent character with respect to others. They are presented in the table associated with a row for convenience, but not for essence. It is important to understand them in the overall set and not to limit them to the specificity of one current of thought. By "inherited traits" we mean those traits that persist significantly in some conventional interpretations of the EE. When we label the traits that would define a genuinely ecological EE and place them in contrast to the "inherited" ones, we do not intend to arrange them as antagonistic poles but as an invitation to a conceptual elaboration that goes from the reception of a conceptual inheritance of a tradition towards its reflective inclusion in a superior concept. For example, we believe that the narrow vision of "anthropocentrism" is based, nonetheless, on legitimate concerns about the life of the human being, and then "ecocentrism" as a pair reflects and includes it in a broader vision.

Table 1. Synthesis of ecophilosophical contributions to Environmental Education.

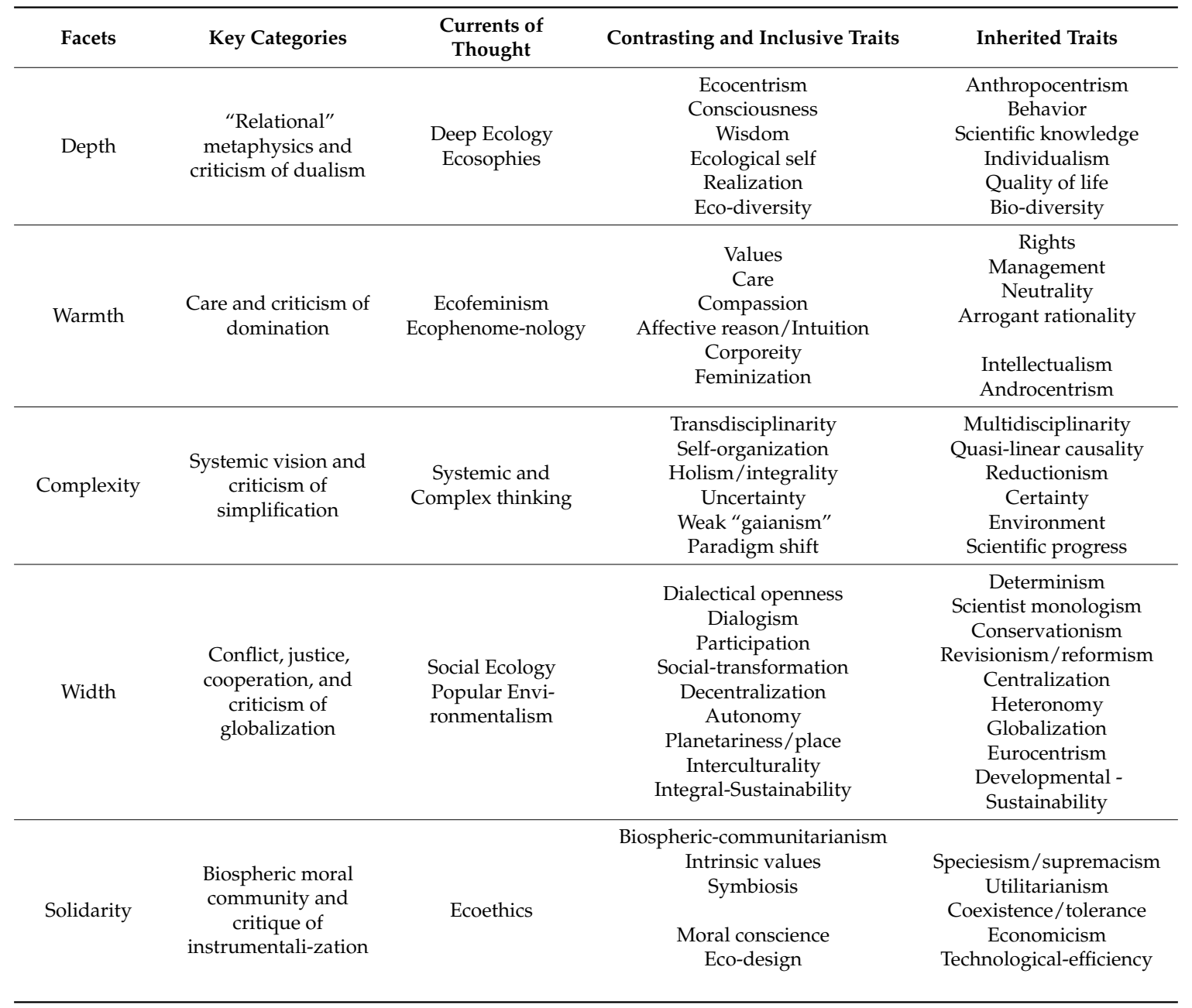


We believe that the educational consequences of these principles are truly serious and they would deserve further research. Nevertheless, we could advance that the educational projects arising from this vision should propose deconstructive strategies of the "inherited traits" to be integrated re-constructively from the suggested inclusive features. Applying this strategy as an expository guideline, we are going to characterize broadly the conceptual framework of an ecocentric EE based on the selected principles and in connection with various proposals in the research of EE.

First, the depth of an ecocentric EE is achieved by overcoming the conceptions of many "environmental" educational proposals that involve a "superficial" and problematic vision of "occasional" environmental issues. In short, for these approaches the important thing is the human being and their quality of life, the central problem is the threat that ecosystems stop providing the services they need (anthropocentrism) and this happens because the aggregate behaviors of citizens - considered merely as individual agents (individualism) - have an effect on the variety and functionality of the environmental mechanisms that we should conserve (biodiversity); and furthermore this is exclusively explained by scientific knowledge.

However, these conceptions of education — to gain depth—need to be overcome and newly conceptualized without being totally denied (ecosystem services, quality of life and bio-diversity are still important). Thus, an ecocentric perspective of EE includes humanistic intentions without a species supremacism [48] and integrates them into a broader aspirational and pedagogical project [49-51]. A project that starts from conceiving the human being interwoven materially, culturally and spiritually with the rest of beings and the Earth [52], and aims to contribute to their mutual "realization" within the framework of a deep eco-diversity [53]. Consciousness, in all its dimensions and in continuity with "place" and "presence", is an outstanding framework of educational work [54], since it seeks to develop a form of wisdom that is transformative because it already functions activating an ecological self [55].

However, we believe that it is not enough to gain depth through an education that refers us fundamentally to the philosophical analysis of those superficial assumptions with which we live [56]. Indeed, that "depth" becomes cold and unable to go deeper without the help of a true "humanity". EE must conceive the human being in their integrity: incarnate and affective [14]. The "inherited" features of that "conventional education" that we have described in contrast to a warm vision represent the features of a patriarchal and androcentric world-view. This conception is characterized by an arrogant rationality supposedly impersonal and decontextualized, which confuses a distanced neutrality with true equanimity. This kind of education adopts these rationalist canons to deal with environmental problems and teaches how to manage them from the parameters of a social world parceled and sufficiently organized by the liberal legal framework $[57,58]$. The natural world can therefore be inserted in this logic; it can be assigned rights and then EE should contribute to its normalization and legitimation. Usually, this conception of education considers the apprentice as part of this abstract scheme. However, a warm EE conceives the learner in their uniqueness and concrete relationship with the world. A relationship that is not abstract, but becomes corporeity and feeling [59]. The world appears in us as a concrete and vivid experience, and activates our genuinely human capacities, those capacities that ecocentric EE must help to realize: particularly compassion [60]. Compassion is not calculation, it is thought and affection that recognizes value. Thus, this EE-in addition to teaching the rights of natural beings- helps develop the ability to estimate the intrinsically valuable in nature and thereby facilitate a relationship of continuous care. In short, the critical and ecocentric EE understands that a true humanization today requires a necessary and positive feminization of our worldview [61].

The world, as we see when gaining depth, is complex. The strategy of hegemonic Western thought has been to deny this complexity and affirm an essential simplicity beyond the senses. The modern world-view exacerbates these tendencies and entrusts any "true" epistemological project to scientific progress. Conventional education has inherited and transmitted the vision of a triumphant "scientism" because of the apparent achievements of the reductionist program and the 
supposed capacity of mechanicism. At the time of gestation of EE, this view of the world already showed clear signs of wear, but a certain education still aligned with this paradigm has insisted on dealing with the notorious contradictions without denying its principles. These educational projects continue to describe life exclusively as an objective thing and place it in a scenario without agency: the environment. The notorious fragmentation of disciplinary knowledge, which manifestly can not account for environmental complexity, is compensated by its juxtaposition in multidisciplinary projects [62,63]. A related education continues to be aligned with a conception of environmental policies where the explanation of environmental problems and possible solutions continues to rest on a naive conception of linear causality. However, the adoption of a systemic approach by critical EE has amply demonstrated the need for a conception of reality in which the idea of self-organization replaces mechanicism and linear causality [64]. This EE entails an integral approach to our terrestrial character and assumes some kind of Gaian vision of being and functioning planetarily [65]. In short, ecocentric EE works fundamentally for a change in our world-view or paradigm $[64,66]$. A new paradigm that tries to account for the relational character of the world from a non-reductionist and transdisciplinary epistemology, capable of assuming the necessary idea that the consciousness of uncertainty should make us more prudent.

On the other hand, the facet of amplitude of ecocentric EE is motivated by the difficulty of achieving the aspirations of "delving without making the hole wider". We do not believe it is possible to advance in the development of an ecological conscience, an intimate ecological self, that does not understand that life is entangled in the conflict arising from "human reflexivity". The most naive modernity stopped in a first reflexive loop, self-satisfied with the supposed certainties and the achievements of the deterministic scientific view. An education aligned with this world-view can hardly avoid the temptation to commit itself to transmit dogmatically "the truth" and apply the procedural formulas dictated by the specialists. Under the reign of certainty, it is difficult for education not to submit to the authority of those who "really" know through the various forms of educative prescriptivism that promote heteronomy and centralization of decisions. A similar approach in environmental policies also has a clear impact on EE, which is urged to enact a merely conservative and static image of nature, conceptualized under the economic interests of Western governs and corporations. This narrow-mindedness is the reflection of a Eurocentric worldview, which, when it takes the form of guilty conscience about the problems that it generates, considers the possible solutions in similar terms: more growth for all, without exceeding the limits of the terrestrial exhaustion. Then, developmentalism legitimates the idea of an education tailored to an economic globalization that is now considered as a "natural law".

However, a critical and ecocentric EE strives not to stop reflective loops and thus to teach the "reflexivity of reflexivity". So, it dismantles the deterministic myths of scientific monologism. The world-because of its complexity and comprehensiveness-is dialectically open. Education teaches us to live in this uncertainty, facilitating the dialogue between knowledge and people [62]. EE must therefore promote autonomy and teach participation to achieve an effective social transformation from decentralized platforms. In this network of singular nodes, EE values and deepens a double sense of identity: that of the culture of the place $[67,68]$ and that of planetariness [69]. Ecocentric EE adopts an intercultural character from the former (singularity), and the consideration of the a "human species among other species" from the later (globality). What defines an ecocentric concept of integral sustainability is to teach and facilitate the perfectiveness of everything that is alive, seeking the balance of this essential tension between locality and globality. Certain (deep) environmentalism may have fallen into the temptation to polarize and assume some kind of misanthropy, or at least conceive a natural purity without the human being. However, the "amplitude" of ecocentric EE prevents us from those forms of purism and elitism that narrow not only the viability of the EE project, but also its ability to develop a sound concept of justice.

An ecocentric perspective implies teaching that our community of life is made up of all terrestrial beings (biospheric communitarianism), that our being is naturally in solidarity with the world around 
it. So there really is no mere community of coexistence, but we live through humanly eligible forms of symbiosis. Then, the ecocentric EE is entrusted to teach how to design those forms of life (and technologies), understanding them critically within a symbiotic community [70]. The core of the ethics taught by this EE is clearly critical with the utilitarian and liberal perspectives, which build coexistence by defining a space of non-aggression that they call "tolerance". The ecocentric EE must go further and promulgate the recognition in the other (human and non-human) of an intrinsic value, which-regardless of the hierarchy of values that is adopted-allows us to develop an intimate respect for the other. In the end, in the depths of a new moral conscience emerges an intimate sense of solidarity, of being "ones" within "diversity", and hence the ecocentric EE must assume facilitating this form of consciousness as an objective.

In short, we consider that the distinctive trait of EE is precisely its ecocentric nature. However, it cannot be said that the radical nature of an ecocentric conception has penetrated the proposals that have been suggested to overcome EE. From a genuinely ecocentric angle, many authors have pointed out the deficits of an EE understood as a "conventional ESD", which is unable to open up to the sense of obligation towards other non-human beings [58,71,72]. The relevance of this debate reveals the resistance to the assimilation of an ecocentric vision in education. To assume this vision is to question many of the basic pillars of the belief system that sustain the anthropocentric morality of our time. So, it seems that although many educational proposals have been mobilized in response to the urgent need of social and environmental challenges, they have done so without the will to assume the transforming depth of ecocentrism, or understanding that the urgency of such responses could be complicated by the seemingly "cumbersome" discourse of the "civilizational and paradigm changes."

\section{Conclusions}

The exposition of clearly ecocentric environmental philosophies-which we have considered as true ecophilosophies-has enabled us to elicit some facets, categories and privileged features for a transition towards a genuinely ecological and ecocentric concept of EE. The information in Table 1 presents a synoptic value and allows a first approach on the viability of a future and more exhaustive project. We believe that from this presentation, researchers and environmental educators have a conceptual framework from which to reflect on their own worldviews or the worldviews of their students and establish, in turn, their theoretical positions with respect to other related educational currents (e.g., ESD, GCE).

We have defended the relevance of a genuinely ecological, "deep" or "dark green" EE that assumes the singular contributions and dialogue between deep ecology, ecofeminism, social ecology, the land ethic and the philosophies of the paradigm shift. The result invites a consideration of EE that is not a mere "application" of the ecophilosophical principles, but it produces new knowledge from the uniqueness of pedagogical thinking and the essential role it plays in the knowledge production of our societies. We believe that—despite relevant and important contributions have been made by the EE tradition—such an EE is not an educational project "yet", but an emergent ecological concept of pedagogy as knowledge truly placed in the physical and social world. We hope that this ecological pedagogy will be developed from a participative approach by researchers and practitioners [73]. On the one hand, we believe that it is necessary to go one step further and encompass ecocentrism in an integral world-view [6-9] (i.e., develop the latent ambition of integrality of genuine EE). On the other hand, we believe that-within this integral framework -it is possible and necessary that researchers and educators affirm themselves as subjects in development [74]. Therefore, future work should focus on proposals for teacher training with a post-formal $[10,11]$ and transformative approach [12-15], and the creation of continuous learning environments for teachers as communities of inquiry. We believe that, from this context, meaningful methodological proposals and coherent practices with an ecocentric and integral vision may emerge.

In summary, this work offers a philosophical framework for an ecocentric development of EE. From here there is considerable work to do in many aspects of greater specificity. However, this work 
has offered a synthetic proposal of principles, whose value and fertility can also be measured in relation to the amount of future work to be done.

Funding: This research received no external funding.

Acknowledgments: I would like to thank my anonymous reviewers for their helpful comments. I am also immensely grateful to María Novo Villaverde, Professor Emeritus and Head of the UNESCO Chair of Environmental Education and Education for Sustainable Development, Universidad Nacional de Educación a Distancia, Spain, for her comments on an earlier version of the manuscript, although any errors are my own and should not tarnish the reputation of this esteemed person. Finally, I would like to thank the Programa de Doctorado en Educación, Escuela Internacional de Doctorado, UNED, for the great support provided.

Conflicts of Interest: The authors declare no conflict of interest.

\section{References}

1. Sauvé, L. Environmental Education and Sustainable Development: A further Appraisal. Can. J. Environ. Educ. 1996, 1, 7-34.

2. UNESCO. Global Citizenship Education: Preparing Learners for the Challenges of the 21st Century; UNESCO: París, France, 2014.

3. Giroux, H.A. Teachers as Intellectuals: Toward a Critical Pedagogy of Learning; Bergin and Garvey Publishing: Westport, CT, USA, 1988.

4. Kincheloe, J.L. Hacia una revisión crítica del pensamiento docente; Octaedro: Barcelona, Spain, 2001.

5. Kincheloe, J.L. Knowledge and Critical Pedagogy: An Introduction; Springer: New York, NY, USA, 2010.

6. Berry, T. The Great Work; Crown Publications: New York, NY, USA, 2000.

7. Boff, L. Cry of the Earth, Cry of the Poor; Orbis Books: New York, NY, USA, 1997.

8. Morin, E. On Complexity; Hampton Press: CressKill, NY, USA, 2008.

9. Esbjorn-Hargens, S.; Zimmerman, M.E. Integral Ecology: Uniting Multiple Perspectives on the Natural World; Integral Books: Boston, MA, USA, 2009.

10. Kincheloe, J.L.; Steinberg, S.R.; Hinchey, P. (Eds.) The Post-Formal Reader: Cognition and Education; Routledge: New York, NY, USA, 2002.

11. Gidley, J.M. Postformal Education: A Philosophy for Complex Futures; Springer: Basel, Switzerland, 2016.

12. O'Sullivan, E. Transformative Learning: Educational Vision for the 21st Century; Zed Books Ltd.: London, UK, 1999.

13. O'Sullivan, E.; Morrell, A.; O'Connor, M.A. (Eds.) Expanding the Boundaries of Transformative Learning: Essays on Theory and Praxis; Palgrave Macmillan: New York, NY, USA, 2002.

14. O'Sullivan, E.; Taylor, M.M. (Eds.) Learning Toward an Ecological Consciousness: Selected Transformative Practices; Palgrave Macmillan: New York, NY, USA, 2004.

15. Cranton, P. Understanding and Promoting Transformative Learning: A Guide to Theory and Practice; Stylus: Sterling, VA, USA, 2016.

16. Sauvé, L. Currents in Environmental Education: Mapping a Complex and Evolving. Can. J. Environ. Educ. 2005, 10, 11-37.

17. SauvÉ, L.; Villemagne, C. La ética ambiental como proyecto de vida y “obra” social: Un desafío de formación. Rev. Cpu-E 2015, 21, 188-209. [CrossRef]

18. Rodman, J. Four Forms of Ecological Consciousness Reconsidered. In Deep Ecology for the Twenty-First Century; Sessions, G., Ed.; Shambhala: New York, NY, USA, 1995; pp. 121-130, (Original work published 1983).

19. Bookchin, M. The Ecology of Freedom: The Emergence and Dissolution of Hierarchy; Cheshire Books: Palo Alto, CA, USA, 1982.

20. Dobson, A.P. Green Political Thought; Routledge: London, UK, 1990.

21. Curry, P. Ecological Ethics; Polity Press: Cambridge, UK, 2011.

22. Naess, A. The Ecology of Wisdom: Writings by Arne Naess; Counterpoint: Berkeley, CA, USA, 2010.

23. Leopold, A. A Sand County Almanac and Other Writings on Conservation and Ecology; Meine, C., Ed.; Library of America: New York, NY, USA, 2013.

24. Callicott, J.B. Companion to A Sand County Almanac: Interpretive and Critical Essays; Univ of Wisconsin Press: Madison, WI, USA, 1987. 
25. Callicott, J.B. In Defense of the Land Ethic: Essays in Environmental Philosophy; SUNY Press: New York, NY, USA, 1989.

26. Leopold, A. The Land Ethic. In Environmental Philosophy: From Animal Rights to Radical Ecology; Pearson/Prentice Hall: Upper Saddle River, NY, USA, 2005; pp. 95-109, (Original work published 1949).

27. Sessions, G. Deep Ecology versus Ecofeminism: Healthy Differences or Incompatible Philosophies? Hypatia 1991, 6, 90-107. [CrossRef]

28. Fox, W. Toward a Transpersonal Ecology: Developing New Foundations for Environmentalism; SUNY: Albany, NY, USA, 1995.

29. Naess, A. The Deep Ecology Movement. In Deep Ecology for the Twenty-First Century; Sessions, G., Ed.; Shambhala: New York, NY, USA, 1995; pp. 64-84, (Original work published 1986).

30. Naess, A. Ecology, Community, and Lifestyle: Outline of an Ecosophy; Cambridge University Press: New York, NY, USA, 1989.

31. Naess, A. Self-Realization: An Ecological Approach to Being in the World. In Deep Ecology for the Twenty-First Century; Sessions, G., Ed.; Shambhala: New York, NY, USA, 1995; pp. 225-239, (Original work published 1986).

32. Devall, B.; Sessions, G. Deep Ecology: Living as if Nature Mattered; Gibbs M. Smith Inc: Salt Lake City, UT, USA, 1987.

33. Capra, F. The Web of Life; Anchor Books: New York, NY, USA, 1996.

34. Morin, E. Introducción al pensamiento complejo; Gedisa: Barcelona, Spain, 2003.

35. Lovelock, J.E. GAIA, a New Look at Life on Earth; Oxford University Press: Oxford, UK, 1979.

36. Margulis, L. Symbiotic Planet: A New Look at Evolution; Basic Books: New York, NY, USA, 1998.

37. Morin, E. Seven Complex Lessons in Education for the Future; UNESCO Publishing: Paris, France, 2001.

38. Meadows, D.; Randers, J. Medows, D. Limits to Growth the 30-Year Update; Earthscan: London, UK, 2005.

39. Hay, P.R. Main Currents in Western Environmental Thought; Indiana University Press: Bloomington, IN, USA, 2002.

40. Novo, M. (Ed.) Mujer y Medio Ambiente: Los caminos de la visibilidad; Los libros de la Catarata: Madrid, Spain, 2007.

41. Plumwood, V. Environmental Culture: The Ecological Crisis of Reason; Routledge: London, UK, 2002.

42. Merchant, C. The Death of Nature: Women, Ecology, and the Scientific Revolution; Harper Collins: New York, NY, USA, 1990.

43. Warren, K.J. Ecological Feminist Philosophies: An Overview of the Issues; Indiana University Press: Bloomington, IN, USA, 1996.

44. Pepper, D. On Contemporary Eco-socialism. In Eco-socialism as Politics; Huan, Q., Ed.; Springer Netherlands: Dordrecht, Netherlands, 2010; pp. 33-44.

45. Bookchin, M. The Philosophy of Social Ecology: Essays on Dialectical Naturalism; Black Rose Books: Montreal, Canada, 1990.

46. Pellow, D.N. What is Critical Environmental Justice? Polity Press: Cambridge, UK, 2017.

47. Martinez Alier, J. The Environmentalism of the Poor: A Study of Ecological Conflicts and Valuation; Edward Elgar Publishing Inc: Cheltenham, UK, 2002.

48. Higgins, C. Humane Education. Educ. Theory 2015, 65, 611-615. [CrossRef]

49. Kahn, R. Towards Ecopedagogy: Weaving a Broad-Based Pedagogy of Liberation for Animals, Nature, and the Oppressed People of the Earth. In The Critical Pedagogy Reader (Vol. 2); Baltonado, M., Torres, E., Eds.; Routledge: New York, NY, USA, 2008.

50. Kopnina, H.; Cherniak, B. Cultivating a Value for Non-Human Interests through the Convergence of Animal Welfare, Animal Rights, and Deep Ecology in Environmental Education. Educ. Sci. 2015, 5, 363-379. [CrossRef]

51. Kopnina, H.; Gjerris, M. Are Some Animals More Equal than Others? Animal Rights and Deep Ecology in Environmental Education. Can. J. Environ. Educ. 2015, 20, 108-122.

52. LaChapelle, D. Educating for Deep Ecology. J. Exp. Educ. 1991, 14, 18-22. [CrossRef]

53. Drengson, A. Education for Local and Global Ecological Responsibility: Arne Næss's Cross-Cultural, Ecophilosophy Approach. Can. J. Environ. Educ. 2000, 5, 13.

54. Dalton, J.E.; Dorman, E.H.; Byrnes, K. The Teaching Self: Contemplative Practices, Pedagogy, and Research in Education; Rowman and Littlefield Education: New York, NY, USA, 2018. 
55. Haigh, M. Deep Ecology Education: Learning from Its Vaisnava Roots. Can. J. Environ. Educ. 2006, 11, 43-56.

56. Næss, A.; Jickling, B. Deep Ecology and Education: A Conversation with Arne Næss. Can. J. Environ. Educ. (Cjee) 2000, 5, 48-62.

57. Kahn, R.V. Critical Pedagogy, Ecoliteracy, and Planetary Crisis: The Ecopedagogy Movement; Peter Lang: New York, NY, USA, 2010.

58. Kopnina, H.; Cherniak, B. Neoliberalism and Justice in Education for Sustainable Development: A Call for Inclusive Pluralism. Environ. Educ. Res. 2016, 22, 827-841. [CrossRef]

59. Sobel, D. Beyond Ecophobia: Reclaiming the Heart in Nature Education; Orion Society: Great Barrington, MA, USA, 1996.

60. Kaza, S. Liberation and Compassion in Environmental Studies. In Ecological Education in Action: On Weaving Education, Culture, and the Environment; SUNY: Albany, New York, USA, 1998.

61. Li, H. Ecofeminism as a Pedagogical Project: Women, Nature, and Education. Educ. Theory 2007, 57, 351-368. [CrossRef]

62. González-Gaudiano, E. Complexity in Environmental Education. Educ. Philos. Theory 2001, 33, $153-166$. [CrossRef]

63. Leff, E. Environmental Knowledge and Education. In Dimensions of Sustainability; Smith, P., Tenner, A., Eds.; Nomos Verlag: Baden-Baden, Germany, 1996.

64. Sterling, S. Whole Systems Thinking as a Basis for Paradigm Cahnge in Education: Explorations in the Context of Sustainability; University of Bath: Bath, UK, 2003.

65. Haigh, M. Gaia: "thinking like a planet" as transformative learning. J. Geogr. High. Educ. 2014, 38, 49-68. [CrossRef]

66. Sterling, S.R. Sustainable Education: Re-visioning Learning and Change; Green Books for the Schumacher Society: Devon, UK, 2001.

67. Bonnett, M. Environmental concern, moral education and our place in nature. J. Moral Educ. 2012, 41, 285-300. [CrossRef]

68. Bonnett, M. Sustainable development, environmental education, and the significance of being in place. Curric. J. 2013, 24, 250-271. [CrossRef]

69. Gadotti, M. Reorienting Education Practices towards Sustainability. J. Educ. Sustain. Dev. 2010, 4, $203-211$. [CrossRef]

70. Jickling, B.; Blenkinsop, S.; Morse, M.; Jensen, A. Wild Pedagogies. Touchstones for Re-Negotiating Education and the Environment in the Anthropocene; Palgrave: London, UK, 2018.

71. Kopnina, H. Education for sustainable development (ESD): The turn away from 'environment' in environmental education? Environ. Educ. Res. 2012, 18, 699-717. [CrossRef]

72. Kopnina, H. Education for sustainable development (ESD) as if environment really mattered. Environ. Dev. 2014, 12, 37-46. [CrossRef]

73. Robottom, I.; Sauvé, L. Reflecting on Participatory Research in Environmental Education: Some Issues for Methodology. Can. J. Environ. Educ. 2003, 8, 111-128.

74. Gough, N. Ignorance in Environmental Education Research. Aust. J. Environ. Educ. 2002, 18, 19-26. [CrossRef]

(C) 2019 by the author. Licensee MDPI, Basel, Switzerland. This article is an open access article distributed under the terms and conditions of the Creative Commons Attribution (CC BY) license (http://creativecommons.org/licenses/by/4.0/). 